\title{
Efficacy of oral treatment with acyclovir and co-trimoxazole in first episode genital herpes
}

\author{
G R KINGHORN,* I ABEYWICKREME,* M JEAVONS,* M ROWLAND,* I BARTON, $\dagger$ AL-HASANI G, $\dagger$ \\ C W POTTER, + AND E HICKMOTT $\ddagger$
}

From the *Department of Genitourinary Medicine, Royal Hallamshire Hospital, Sheffield, the †Department of Virology, University of Sheffield Medical School, Sheffield, and the $\ddagger$ Clinical and Applied Research Division, Wellcome Research Laboratories, Beckenham, Kent

SUMMARY Forty patients presenting with first episode genital herpes were randomly allocated to seven day treatment with oral acyclovir alone, placebo alone, oral acyclovir plus co-trimoxazole, or placebo plus co-trimoxazole. Patients receiving acyclovir had significantly shorter periods of viral shedding $(\mathrm{p}<0.001)$, pain $(\mathrm{p}=0.03)$, and times to lesion healing $(\mathrm{p}<0.05)$. Averaged over all patients there was no evidence that co-trimoxazole affected any of the variables, though in women cotrimoxazole was associated with a shorter time to lesion healing $(p<0 \cdot 01)$. Furthermore, the combination treatment gave significantly shorter times to lesion healing than acyclovir alone, placebo alone, or placebo and co-trimoxazole $(\mathrm{p}=0.01)$ and good trends elsewhere (external lesions and duration of pain). Neither drug was associated with any adverse events or toxicity or influenced the subsequent recurrence rate.

\section{Introduction}

The number of patients with genital herpes attending clinics in the United Kingdom is rapidly increasing. First episodes are often severe, and their management may necessitate hospital admission. Until recently treatment was largely symptomatic and consisted primarily of providing adequate analgesia and control of secondary bacterial infection of lesions by frequent saline baths combined with systemic antibiotics. Cotrimoxazole, which does not interfere with investigations for syphilis, has often been the preferred antibiotic. Roy, however, was unable to show any appreciable effect on the duration of symptoms or time to healing produced by co-trimoxazole in first episode genital herpes. ${ }^{1}$

The introduction of acyclovir now offers effective antiviral treatment of genital herpes. Recent studies have shown antiviral activity producing clinical benefit when acyclovir has been administered either intravenously, ${ }^{2}$ topically, ${ }^{3}{ }^{4}$ or orally ${ }^{6}$ in first episodes.

Recent studies in Sheffield have shown that herpetic ulcers often contain a polymicrobial pathogenic flora, ${ }^{7} 8$ though the clinical importance of these

Address for reprints: Dr GR Kinghorn, Department of Genitourinary Medicine, Royal Hallamshire Hospital, Glossop Road, Sheffield S10 2JF.

Accepted for publication 21 July 1985 observations is not clear. We therefore investigated the efficacy of oral acyclovir and co-trimoxazole, alone and in combination, in treating first episode genital herpes.

\section{Patients and methods}

STUDY POPULATION

Men and women aged 16 or more, who presented to the department of genitourinary medicine in Sheffield within six days of the onset of symptoms of first episode genital herpes and who gave informed consent, were entered into the study. Patients who had used other antiviral or immune stimulation treatment within the preceding seven days, who had underlying immune deficiency, or hepatic or renal disease were excluded, as were women inadequately protected against pregnancy.

\section{STUDY DESIGN AND PATIENT ASSESSMENTS}

Patients were randomly allocated (with separate stratification for men and women) to one of four treatment groups treatment receiving: acyclovir tablets (Zovirax, Wellcome) $200 \mathrm{mg}$ five times daily for seven days; placebo tablets identical to acyclovir taken five times daily for seven days; acyclovir tablets in the above dosage plus co-trimoxazole tablets (Septrin, Wellcome; $160 \mathrm{mg}$ trimethoprim and $800 \mathrm{mg}$ sulphamethoxazole) twice daily for seven days; or placebo tablets identical to acyclovir taken five times 
daily for seven days plus co-trimoxazole in the above dosage twice daily for seven days. Patients in all four treatment groups were given identical advice -regarding additional symptomatic treatment.

All study entrants were subject to an initial clinical evaluation at which the presence of local and systemic symptoms and the extent of lesions were assessed and recorded in a standardised manner. After the start of treatment they were reassessed three times a week for the first two weeks after presentation and thereafter. twice weekly until complete resolution of symptoms and healing of lesions had occurred.

Compliance with treatment was routinely assessed at each visit by counting the number of tablets taken. Adverse events during the study period were recorded at each assessment visit.

\section{LABORATORY STUDIES}

At each clinical assessment, separate swabs were taken for viral cultures from external genital lesions and from the cervix in women or the urethra in men. Representative isolates from each patient were typed and identified as either herpes simplex virus (HSV) type 1 or HSV-2. The method of viral culture and typing have been described previously. ${ }^{9}$

Serum specimens collected from each patient both at study entry and during convalescence 21 days later were examined for specific HSV microneutralisation antibodies. Patients with antibody titres of less than $1 / 10$ against both $\mathrm{HSV}-1$ and $\mathrm{HSV}-2$ in serum taken at the acute stage were defined as having true primary infections.

As part of toxicity screening, blood specimens were collected at entry and three days after the end of drug treatment for routine haematology and clinical chemistry tests. Urine analysis was regularly performed during the study period.
FOLLOW UP FOR RECURRENCES

After completing the study, all patients were asked to report back to the clinic in the event of any recurrence and routinely at three, six, and 12 months after entry.

\section{STATISTICAL ANALYSIS}

Patients were initially grouped into those who received acyclovir and those who received placebo, then regrouped into whether or not they received cotrimoxazole. The respective groups in each analysis were compared for their demographic and clinical data at study entry using Fisher's exact test and the Mantel Cox statistic. Efficacy was analysed by comparing treatment groups using survival analysis techniques based on the Cox proportional hazards regression model. Patients' sex, treatment with acyclovir, or treatment with co-trimoxazole were considered as factors. $p$ Values were estimated from the likelihood ratio test.

\section{Results}

COMPARISONS OF TREATMENT GROUPS

Forty patients entered the study, but two were withdrawn from analysis because they failed to comply with the protocol. A total of 38 (18 men and 20 women) completed the study as planned, 10 of whom received acyclovir alone, 10 received placebo alone, nine received acyclovir plus co-trimoxazole, and nine received placebo plus co-trimoxazole.

Table I compares the characteristics of the treatment groups at presentation. There were no significant differences between patients who received acyclovir or placebo, or between patients who were treated or not with co-trimoxazole.

Overall $29(76 \%)$ patients had true primary infections. Positive viral cultures were obtained from

TABLE I Comparison of treatment groups at presentation with genital herpes

\begin{tabular}{|c|c|c|c|c|}
\hline \multirow[b]{2}{*}{ Characteristics } & \multicolumn{4}{|c|}{ Patients* who received: } \\
\hline & $\begin{array}{l}\text { Acyclovir } \\
(n=19)^{*}\end{array}$ & $\begin{array}{l}\text { Placebo } \\
(n=19)^{*}\end{array}$ & $\begin{array}{l}\text { Co-trimoxazole } \\
(n=18)^{*}\end{array}$ & $\begin{array}{l}\text { No } \\
\text { co-trimoxazole } \\
(n=20)^{*}\end{array}$ \\
\hline $\begin{array}{l}\text { No of men } \\
\text { No of women } \\
\text { Mean (SEM) age (years) } \\
\text { Mean (SEM) symptom duration (days) } \\
\text { Mean (SEM) lesion duration (days) } \\
\text { No }(\%) \text { with inguinal lymphadenitis } \\
\text { No }(\%) \text { with true primary (antibody negative) infection } \\
\text { No }(\%) \text { of positive cultures } \\
\text { No }(\%) \text { of HSV-1 isolates }\end{array}$ & $\begin{array}{l}9 \\
10 \\
23 \cdot 2(1 \cdot 18) \\
3 \cdot 9(0 \cdot 41) \\
2 \cdot 7(0 \cdot 40) \\
14(74) \\
13(68) \\
16(84) \\
9(47)\end{array}$ & $\begin{array}{l}9 \\
10 \\
23 \cdot 3(1 \cdot 15) \\
4 \cdot 9(0.62) \\
3 \cdot 0(0 \cdot 41) \\
17(89) \\
17(89) \\
19(100) \\
8(42)\end{array}$ & $\begin{array}{l}10 \\
8 \\
23 \cdot 4(1 \cdot 31) \\
4 \cdot 7(0 \cdot 69) \\
2 \cdot 7(0 \cdot 25) \\
17(94) \\
14(78) \\
16(89) \\
9(50)\end{array}$ & $\begin{array}{l}8 \\
12 \\
23 \cdot 4(1 \cdot 02) \\
4 \cdot 2(0 \cdot 32) \\
3 \cdot 1(0 \cdot 53) \\
14(70) \\
16(80) \\
19(95) \\
8(40)\end{array}$ \\
\hline
\end{tabular}



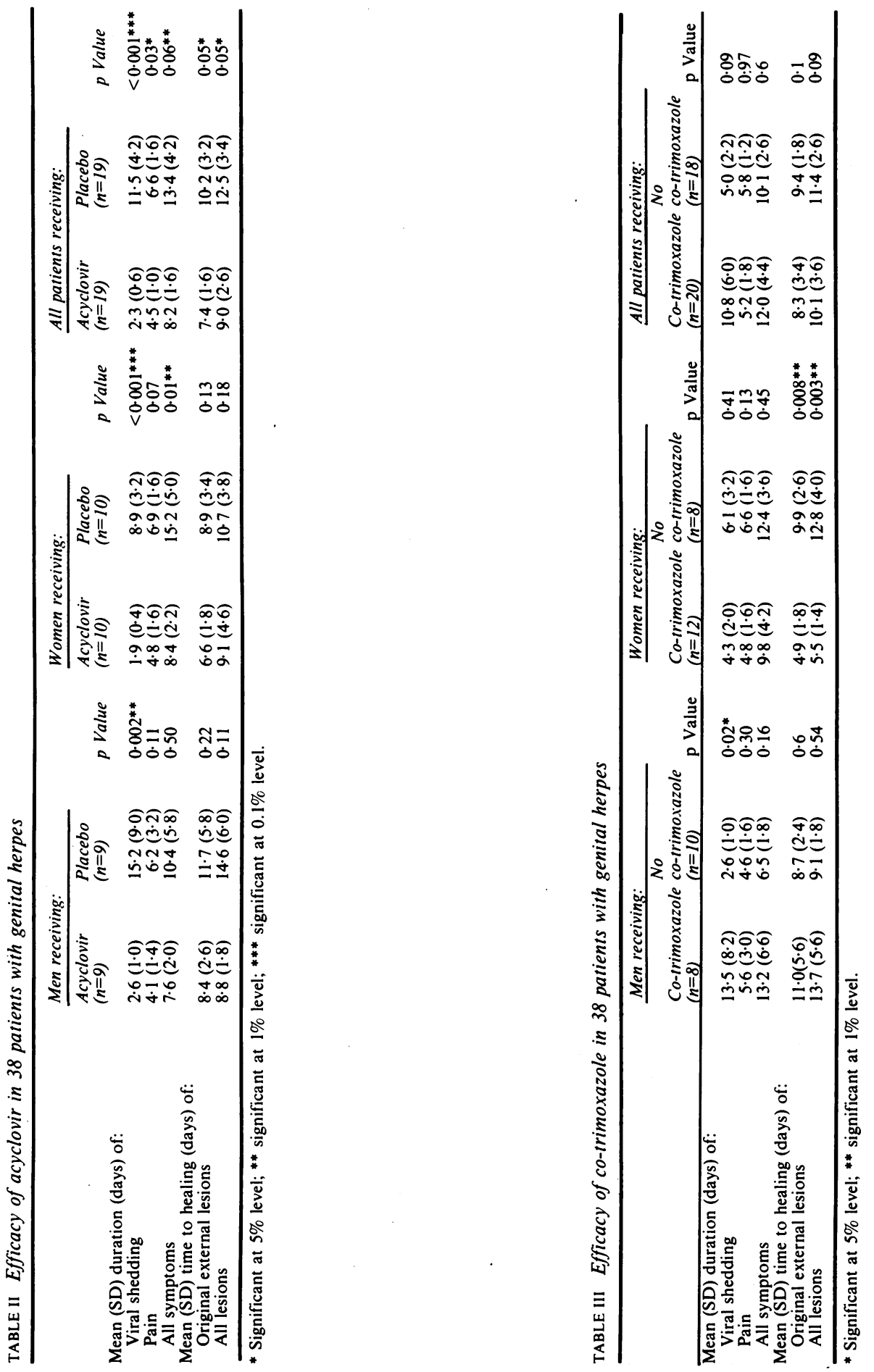

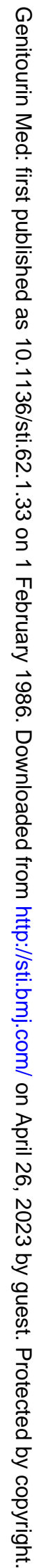


$35(92 \%)$, and the diagnosis in the three culture negative patients was confirmed by fourfold rises in HSV antibody titres in their serum samples when convalescent. HSV-1 was isolated from 17 (49\%) of the culture positive patients.

\section{EFFICACY OF ACYCLOVIR}

Table II shows the mean (SD) duration of viral shedding and symptoms and time to healing in men, women, and all patients treated with acyclovir or placebo. For each sex alone, all variables were of shorter duration in the acyclovir treated patients. Significance was attained for the shorter duration of viral shedding in men $(p<0.01)$ and in women $(p<0.001)$ and the shorter duration of all symptoms in women $(p=0.01)$. When the combined results in both sexes were compared, the acyclovir treated patients had significantly shorter durations of viral shedding $(p<0.001)$ and pain $(p<0.05)$ and shorter times to healing of external genital lesions $(p<0.05)$ and of all lesions $(\mathrm{p}<0.05)$.

\section{EFFICACY OF CO-TRIMOXAZOLE}

Table III shows the corresponding data for patients treated with and without co-trimoxazole. For men alone, the duration of viral excretion in those treated with co-trimoxazole was significantly longer $(p<0 \cdot 05)$, though none of the differences in clinical variables achieved significance. The results in women treated with co-trimoxazole were noticeably different. All variables were of shorter duration in treated compared with untreated women. The differences in time to healing of external genital lesions and all lesions were both significant $(\mathrm{p}<0.01)$. When the results in all patients were compared, no variables showed significant differences between treated and untreated patients.

INTERACTION BETWEEN ACYCLOVIR AND COTRIMOXAZOLE

Table IV shows the mean (SD) values for the duration of viral shedding and symptoms and times to healing of lesions for each of the four treatment groups. Each of the clinical variables was shorter in patients receiving both treatments. The shorter time to complete healing of all lesions in patients receiving combination treatment was significant $(p<0.01)$ when compared with the corresponding times for each of the other treatment groups.

\section{RECURRENCES}

Table $\mathrm{V}$ shows that recurrences were experienced by one $(7 \%)$ of 15 patients with HSV-1 first episodes compared with $15(83 \%)$ of 18 patients with HSV-2 first episodes $(p<0.001)$ who attended for the follow up period. There were no significant differences between the treatment groups in the recurrence rate.

\section{ADVERSE EVENTS}

No adverse events were reported by patients in any of the treatment groups. All values for haematological variables and biochemical data remained within their normal ranges after treatment.

\section{Discussion}

We found that oral acyclovir treatment in first episode genital herpes is associated with an appreciable

TABLE IV Interactive effects of acyclovir and cotrimoxazole in 38 patients with genital herpes

\begin{tabular}{|c|c|c|c|c|c|}
\hline & $\begin{array}{l}\text { Acyclovir plus } \\
\text { co-trimoxazole } \\
(n=9)\end{array}$ & $\begin{array}{l}\text { Acyclovir } \\
\text { alone } \\
(n=10)\end{array}$ & $\begin{array}{l}\text { Placebo plus } \\
\text { co-trimoxazole } \\
(n=9)\end{array}$ & $\begin{array}{l}\text { Placebo } \\
\text { alone } \\
(n=10)\end{array}$ & $\begin{array}{l}\text { Overall } \\
\text { p Value }\end{array}$ \\
\hline \multicolumn{6}{|l|}{ Mean (SD) duration (days) of: } \\
\hline Viral shedding & $2 \cdot 7(1 \cdot 2)$ & $1.9(0.4)$ & $17 \cdot 3(9 \cdot 3)$ & $7 \cdot 7(3 \cdot 5)$ & $0.001^{* *}$ \\
\hline Pain & $3.9(1.5)$ & $5.0(1.4)$ & $6.6(3.0)$ & $6.6(1.9)$ & 0.15 \\
\hline All symptoms & $7.6(2.9)$ & $8 \cdot 7(1 \cdot 3)$ & $15 \cdot 3(6 \cdot 4)$ & $11 \cdot 2(5 \cdot 0)$ & 0.26 \\
\hline \multicolumn{6}{|l|}{ Mean (SD) time to healing (days) of: } \\
\hline Original external lesions & $5.8(1.8)$ & $9.0(2 \cdot 2)$ & $10 \cdot 8(6 \cdot 3)$ & $9 \cdot 7(2 \cdot 8)$ & 0.09 \\
\hline All lesions & $6 \cdot 1(1 \cdot 7)$ & $11.5(3.9)$ & $14.4(6.2)$ & $11 \cdot 2(3.5)$ & $0.01^{*}$ \\
\hline
\end{tabular}

${ }^{*}$ Significant at $1 \%$ level; ${ }^{* *}$ significant at $0.1 \%$ level.

TABLE V Proportion of patients experiencing recurrence within one year according to type of virus causing first episode of genital herpes

\begin{tabular}{|c|c|c|c|c|}
\hline \multirow[b]{2}{*}{$\begin{array}{l}\text { Causative } \\
\text { virus type }\end{array}$} & \multicolumn{4}{|c|}{ No (\%) experiencing recurrences/No who had received: } \\
\hline & $\begin{array}{l}\text { Acyclovir } \\
(n=15)\end{array}$ & $\begin{array}{l}\text { Placebo } \\
(n=18)\end{array}$ & $\begin{array}{l}\text { Co-trimoxazole } \\
(n=17)\end{array}$ & $\begin{array}{l}\text { No } \\
\text { co-tromixazole } \\
(n=16)\end{array}$ \\
\hline $\begin{array}{l}\text { HSV-1 } \\
\text { HSV-2 }\end{array}$ & $\begin{array}{l}1 / 8 \\
7 / 7\end{array}$ & $\begin{array}{l}0 / 7 \\
8 / 11\end{array}$ & $\begin{array}{l}1 / 8 \\
7 / 9\end{array}$ & $\begin{array}{l}0 / 7 \\
8 / 9\end{array}$ \\
\hline Total & $8 / 15(53)$ & $8 / 18(44)$ & $8 / 17(47)$ & $8 / 16(50)$ \\
\hline
\end{tabular}


reduction in the duration of viral shedding compared with that in placebo treatment. The pronounced antiviral effect was accompanied by noticeable clinical benefits in terms of reduced duration of pain and time to complete healing of lesions. In women an appreciable reduction in the duration of all symptoms was also shown. These results are similar to those in other studies reporting the efficacy of oral acyclovir in first episode genital herpes. It is interesting to note that in the study performed by Bryson et $^{-6} l^{6} 43$ of their 48 patients were infected with HSV-2 compared with only 18 of 35 patients in our study.

The antiviral effect of oral acyclovir is much more pronounced than that produced by topical acyclovir. The median duration of viral shedding from patients treated with oral acyclovir was two days compared with a median duration of four days in patients treated with topical acyclovir reported in a previous study. ${ }^{4}$ The effects on viral shedding, duration of symptoms, and time to healing of lesions produced by oral acyclovir are similar to those reported by Mindel et al using intravenous treatment. ${ }^{2}$ The obvious advantage of oral acyclovir is that it allows most of those suffering from first episode genital herpes to be treated as outpatients. We found no evidence of adverse events or toxicity associated with oral acyclovir treatment.

In contrast, patients treated with co-trimoxazole did not differ appreciably from those who did not receive the drug in the duration of their symptoms or time to healing. The results in both sexes combined, however, may have been influenced by the very much longer duration of viral shedding in men receiving cotrimoxazole for whom, not surprisingly, all the clinical variables were of longer duration. In women the duration of viral shedding was similar in both groups, but the use of co-trimoxazole was associated with an appreciable reduction in time to healing for all lesions.

A significant interactive effect was shown for combination treatment with acyclovir and cotrimoxazole in patients with regard to a reduced time to healing of lesions when compared with each of the other three treatment groups. These observations require cautious interpretation as the number of patients in each treatment group was small and some bias may have been introduced by the investigators being aware of which patients had been randomly allocated to co-trimoxazole treatment. Nevertheless, the results suggest that secondary bacterial infection of herpetic lesions is of clinical importance and may delay the time to complete healing, though it seems likely that the duration of viral shedding is of paramount importance in the resolution of lesions.

The relevance of antibacterial treatment to the management of first episode genital herpes in other geographical areas needs to be investigated further. It may only be of local importance as, though recent
Sheffield studies have shown a high prevalence of Haemophilus ducreyi and other bacterial pathogens in herpetic ulcers, the results were not confirmed in studies elsewhere in the United Kingdom. 10-12 Nevertheless, the concomitant use of acyclovir and antibiotic treatment is likely to be of benefit in patients with first episode initial herpes living in areas where chancroid is endemic. It would also be interesting to study the respective efficacies of antiviral and antibiotic treatment in patients who present more than six days after the onset of their lesions. We suggest that, in future studies of antiviral treatment of genital herpes, the concomitant use of antibiotics should be recorded.

Neither acyclovir nor co-trimoxazole treatment, alone or in combination, appears to influence the recurrence rate of genital herpes. Our results confirm that the typing of the causative virus isolate is of greater prognostic significance, as recurrences were rare after HSV-1 first episodes but usual after HSV-2 first episodes.

We thank Dr A P Fiddian and Mr D Jones from the Wellcome Foundation for their advice and help with this study, and Mrs L D Arnold for typing the manuscript.

\section{References}

1. Roy RB. Double-blind placebo-controlled study of the use of cotrimoxazole in the treatment of primary herpes genitalis. British Journal of Sexual Medicine 1982;9:22,41.

2. Mindel A, Adler MW, Sutherland S, Fiddian AP. Intravenous acyclovir treatment for primary genital herpes. Lancet 1982;i:697-700.

3. Thin RN, Nabarro JM, Davidson-Parker J, Fiddian AP. Topical acyclovir in the treatment of initial genital herpes. British Journal of Venereal Diseases 1983;59:116-9.

4. Kinghorn GR, Turner EB, Barton IG, Potter CW, Burke CA, Fiddian AP. Efficacy of topical acyclovir cream in first and recurrent episodes of genital herpes. Antiviral Res 1983;3:291301.

5. Nilsen AE, Aasen R, Halsos AM, et al. Efficacy of oral acyclovir in the treatment of initial and recurrent genital herpes. Lancet 1982;ii:571-3.

6. Bryson $\mathrm{YJ}$, Dillon $\mathrm{M}$, Lovett $\mathrm{M}$, et al. Treatment of first episodes of genital herpes simplex virus infection with oral acyclovir. $N$ Engl J Med 1983;308:916-21.

7. Kinghorn GR, Hafiz S, McEntegart MG. The pathogenic microbial flora of genital ulcers in Sheffield with particular reference to herpes simplex virus and Haemophilus ducreyi. British Journal of Venereal Diseases 1982;58:377-80.

8. Masfari AN, Kinghorn GR, Hafiz S, Barton IG, Duerden BI. Anaerobic bacteria and herpes simplex virus in genital ulceration. Genitourin Med 1985;61:109-13.

9. Barton IG, Kinghorn GR, Najem S, Al.Omar LS, Potter CW. Incidence of herpes simplex virus types 1 and 2 isolated in patients with herpes genitalis in Sheffield. British Journal of Venereal Diseases 1982;58:44-7.

10. Mallard RH, Macauley ME, Riordan T, Chowdhury FH, Chandiok S, Bhattacharyya MN. Haemophilus ducreyi infection in Manchester. Lancet 1983;ii:283.

11. Forster GE, Karim QN, White KB, Harris JRW. Isolating Haemophilus ducreyi. Lancet 1983;ii:910.

12. Sprott MS, Pattman RS, Richardson IR, Schofield CBS, Saravandamettu KM. Haemophilus ducreyi and genital ulcers. Lancet 1983;ii:1302-3. 